\title{
Entre lo editado y lo leído en la Facultad de Filosofía y Letras de la Universidad de Buenos Aires Hacia un debate de su marco teórico metodológico y de sus fuentes documentales desde la Historia de la Lectura
}

\section{Alejandro E. Parada}

Universidad de Buenos Aires. Facultad de Filosofia y Letras. Departamento de Bibliotecologìa y Ciencia de la Información. Buenos Aires, Argentina. Universidad de Buenos Aires. Facultad de Filosofía y Letras. Instituto de Investigaciones Bibliotecológicas (INIBI). Buenos Aires, Argentina | aparada@filo.uba.ar / http://orcid.org/oooo-0002-2331-442X

\author{
Beatriz C. Valinoti \\ Universidad de Buenos Aires. Facultad de Filosofia y Letras. Departamento de Bibliotecologìa y Ciencia de la Información. \\ Buenos Aires, Argentina. I bvalinoti@filo.uba.ar/http://orcid.org/oooo-0oo3-2569-4187
}

\section{Resumen}

El presente artículo, elaborado en el marco de la programación FILO:CyT (UBA), intenta iniciar una discusión sobre la fundamentación teórico metodológica de su propio objeto de estudio. Al investigar Entre lo editado y lo leido en la Facultad de Filosofía y Letras de la Universidad de Buenos Aires, se abordan una serie de temáticas para reflexionar acerca de la Historia de la Edición, la Historia del Diseño Gráfico y la Historia de la Lectura en esa casa de estudios durante el período 1896-2019. Desde este contexto, articulado por la Historia de la Cultura Escrita, se desarrollan, para poner en debate, los siguientes tópicos: la construcción de una teoría indispensable para llevar a cabo dicho proyecto, la variedad y diversidad de las fuentes documentales existentes en la facultad, y la metodología con la cual instrumentar esta problemática, entre otros aspectos. Finalmente, se señala la necesidad de buscar una configuración conceptual con el objetivo de compararla, discutirla y adaptarla a otras universidades de la Argentina interesadas en estos estudios culturales y, especialmente, resaltar la importancia de establecer, en los ámbitos académicos, modelos conceptuales similares para analizar la Historia de la Edición, del Diseño Gráfico y de la Lectura en la esfera universitaria.
Palabras clave

Historia de la Cultura Impresa Historia de la Edición Historia de la Lectura Historia del Diseño Gráfico Publicaciones

Universidad de Buenos Aires Facultad de Filosofía y Letras 


\section{Between what was edited and what was read in the Facultad de Filosofía y Letras de la Universidad de Buenos Aires. Some steps towards a debate of its methodological-theoretical framework, and its documentary sources from the History of Reading}

\section{Abstract}

Keywords

Printed Culture History Edition History

Reading History History of Publishing

Graphic Design

Publications

Universidad de Buenos Aires Facultad de Filosofía y Letras
This article, developed within the framework of the FILO:CyT $(U B A)$ programming, attempts to generate discussion on the theoretical-methodological foundation of its own object of study. In researching Between what was edited and what was read in the Facultad de Filosofia y Letras de la Universidad de Buenos Aires, a number of topics are addressed to reflect on the History of Publishing, the History of Graphic Design and the History of Reading in the same faculty during the period 1896-2019. In this context, the following topics are developed for future discussion, articulated by the History of Written Culture: the construction of an indispensable theory to carry out the project, the variety and diversity of the existing documentary sources in the faculty, and the methodology appropriate for this problem, among other aspects. Finally, it is pointed out the need to search for a conceptual configuration in order to compare it, discuss it and adapt it to other universities in Argentina interested in these cultural studies, high lighting the importance of establishing similar conceptual models to analyze the History of Publishing, Graphic Design and Reading in the university sphere, in academic settings.

Artículo recibido: 22-10-2021 Aceptado: 15-11-2021

\footnotetext{
1. Este proyecto se encuentra en su etapa de desarrollo final en el marco de los Proyectos FILO:CyT (FC19-031), "Editar y leer en la Universidad. Una historia de la edición académica de la Facultad de Filosofía y Letras (UBA) desde la Historia de la Lectura", (Universidad de Buenos Aires. Facultad de Filosofía y Letras, Instituto de Investigaciones Bibliotecológicas. INIBI.) Duración: 2019-2021. Director: Alejandro E. Parada / Co-directora: Beatriz C. Valinoti. Participantes: Graciela M. Giunti, Silvia Contardi, Ivalú Ramírez Ibarra, Faustino Chirino, y Matilde Oliveros.
}

\section{Tras la búsqueda de un entorno conceptual en la edición y la lectura en la Facultad de Filosofía y Letras}

Delimitar y debatir un proyecto que abarca el mundo de la edición académica y la lectura en la esfera de la Facultad de Filosofía y Letras (FFyL-UBA) ${ }^{1}$ es, sin duda alguna, un emprendimiento arduo y ambicioso, con una gran cantidad de enfoques de compleja resolución. Por otra parte, las realidades de edición y de lectura se encuentran atravesadas por itinerarios e intereses divergentes según las disciplinas desde las cuales se las estudie. Travesías que, en muchas ocasiones, responden a cierta lógica pero que, en otras oportunidades, están ceñidas por el azar o responden a las intencionalidades y tensiones humanas propias de todo colectivo universitario. A todo esto debe agregarse el hecho de que una Universidad no es un centro de aprendizaje y de producción de conocimiento aislado del contexto social, económico y político, y que estos inciden y presionan sobre sus producciones escritas y sus prácticas de lectura.

Es por todo esto y debido a una verdadera constelación de abordajes posibles que, al invocar el verbo "delimitar" se intenta esbozar una de las posibles aproximaciones a este objeto de estudio para desarrollar un debate que permita enriquecer las miradas. Es decir, la limitación como ambivalencia deviene también en una forma de acceso y, más específicamente, uno de los muchos caminos y procederes para reflexionar sobre la heterogénea expansión de esta clase de estudios. Este trabajo, entonces, solo trata de incursionar en una senda de interpretación entre las muchas factibles. 
Hecha esta salvedad se impone una primera pregunta de fuerte índole desafiante: ¿cuál podría ser el marco teórico en que se sustentaría esta primera aproximación?, y a partir de ella otras cuestiones no menos significativas, ¿qué fuentes documentales se requieren para encarar los temas de edición en esta casa de estudios y mediante qué procedimientos y representaciones los lectores universitarios acceden e interpretan sus discursos? Y, a posteriori, ¿con qué herramientas metodológicas abordarlo? Como se observa nos hallamos ante un tema que deviene en algo no menor y que, alejado de cualquier superficialidad, releva una enorme dificultad, a partir de que su magnitud cualitativa excede lo cuantitativo.

Además, y en apariencia, desde el ámbito teórico se presentaría una contradicción entre el universo de la edición y las prácticas de los lectores. Esto puede fundamentarse en la operatividad pragmática editorial, fuertemente pautada por los círculos de distribución de libros y el aspecto contundente de que, en este circuito, el texto impreso se impone, en su plena materialidad como mercancía. En cambio, la Historia de la Lectura, tal como la han definido varios autores, es una búsqueda de las presentaciones del acto de leer y cómo este ha influido en las vidas de las personas, cualesquiera sea su género y corte etario. Pero decimos aparentemente porque cuando se habla de Historia de la Edición e Historia de la Lectura, no se las entiende como dos trayectorias independientes, sino que permite referirse a una macro disciplina que las enlaza y las incluye: aquello que se denomina la Historia de la Cultura Escrita o para otros la Historia Social de la Cultura Escrita (Castillo Gómez, 2003 y 2015; Chartier, 2008; Chartier y Hébrard, 1999; Petrucci, 1999 y 2002: 19).

Y más puntualmente, el presente proyecto se encuadra en los dominios de la Historia de la Cultura Impresa, tal como lo señala Valinoti en su configuración del campo bajo la expresión global de "prácticas culturales asociadas a la cultura de lo impreso" (Valinoti, 2013: 73). La Facultad de Filosofía y Letras, como todas las unidades universitarias desde sus inicios hasta principios del siglo XXI, hizo de la civilización impresa su epicentro medular, en el cual giraron todas las prácticas de estudio, docencia, aprendizaje y extensión.

Por otra parte, entre las diversas y ricas características de historiar la edición, es imperioso resaltar, entre muchas peculiaridades cualitativas, que los historiadores editoriales rescatan la gestación de las redes intelectuales del libro (Chicote, 2015) y, además, tal como lo ha observado Donald McKenzie (2005), subrayar que la puesta en texto material de los impresos es una de las tantas formas de construir lectores. Por lo tanto, existen fuertes vínculos y articulaciones que enlazan en una sola trama la edición y las lecturas. Cuando desarrollamos estos dos campos, en definitiva, nos estamos refiriendo, conviene repetirlo, a la Historia de la Civilización Escrita en general y a su manifestación específica como es la Historia de la Cultura Impresa.

En consecuencia, dejando de lado las particularidades propias de cada una, al establecer su marco teórico nos sumergimos en ese contexto histórico que totaliza las variaciones escritas en su amplio espectro. Así, apropiaciones, prácticas, representaciones, capturas de los discursos por los lectores configuran un amplio territorio compartido entre el libro editado y su larga historia en el momento de vincularse con la lectura. El marco teórico, de ese modo, en estas instancias modernas de interpretar los textos, involucra a ambos campos y los une en una dinámica dialéctica que los hace inseparables. En este itinerario, al hacer Historia de la Lectura emprendemos una Historia de la Edición y, recíprocamente, al instrumentar la Historia de la Edición establecemos los puentes que la enlaza con la Historia de la Lectura.

Del punto de vista de las ideas editoriales es significativo tratar de responder mediante qué procedimientos y a través de qué prácticas operaron los editores en nuestra 
geografía universitaria y, si bien se piensa específicamente en la Facultad de Filosofía y Letras de la Universidad de Buenos Aires, la idea es generar herramientas que permitan historiar más de un caso.

Esta fundamentación teórica debe, en primera instancia, circunscribirse a la "duración", esto es, a la esfera real de un período histórico. Así, el recorte temporal que estamos analizando se extiende desde 1896 hasta 2019. Un interregno de más de 120 años en el cual se sucedieron todo tipo de innovaciones en el área editorial. Esas novedades tecnológicas que impulsan la producción de libros, estuvieron influidas por distintos movimientos filosóficos, ideológicos, arquitectónicos, sociales y económicos, que en líneas muy generales abarcaron desde el positivismo hasta el actual posmodernismo. Aquello que hace un pasado no muy lejano se denominaba Historia de las Ideas puede ser de gran ayuda para desentrañar cómo influyeron algunas concepciones en el pensamiento editorial universitario. Y no solo nos referimos al hecho de publicar de un determinado modo o implementar cierto diseño, influido por ejemplo por el modernismo o la bauhaus (Sudjic, 2014) sino, también, a develar esas expresiones en las formas de producción gráfica y distribución académica.

Otro punto que debe dirimir el marco teórico es la problemática de "la espacialidad y territorialidad editorial". Porque el espacio de edición se relaciona íntimamente con las decisiones políticas y de poder (Sassen, 2010 y 2012). Es decir, en qué momentos y bajo qué mandatos de planificación universitaria se tomó la decisión de contratar editoriales comerciales y privadas para publicar los libros realizados en la FFyL y, por el contrario, en qué época se tomó la decisión de poseer una imprenta en la Facultad para imprimir "puertas a dentro" las propias obras. Porque si bien esto responde a una operatividad de uso práctico, sin duda, es una toma de posición en la esfera de las ideas y responde a determinados delineamientos ideológicos que es menester dilucidar.

A todo esto será necesario apelar a la diversidad de la construcción de los distintos campos y materias que se impusieron en la Facultad, en esa pujante y típica lucha por la identidad disciplinar en gestación (Bourdieu, 1999 y 2002). Territorios, geografías, campos y disciplinas que nacieron y se desarrollaron a lo largo de más de un siglo y cuyas improntas han quedado presentes, de una o de otra forma, en la Historia de la Edición en la Facultad.

Entre los muchos aspectos a tener en cuenta, ciertamente, tres acercamientos son significativos en la articulación conceptual de la edición y la lectura: la Historia Política, la Historia Social y la Historia de las Instituciones. Pero no se trata únicamente de identificar las condiciones y características de las migraciones y giros políticosociales e institucionales en el transcurso de esa centuria sino, además, de identificar las distintas escuelas historiográficas que interpretaron esos acontecimientos. Como es bien sabido cada historiografía se funda en sus propios mandatos teóricos y, en consecuencia, sus conclusiones pueden ser similares o arribar a conjeturas opuestas.

Esta mínima regulación teórica, en lo sustancial, deberá desenvolverse en una dimensión particularmente importante: ¿cuáles fueron las mutaciones y los sucesivos giros de las Humanidades y las Ciencias Sociales en las carreras de la Facultad? Porque los aportes epistemológicos y ontológicos reconfiguraron, a lo largo y a lo ancho de nuestra vida académica, la integridad de las asignaturas y las carreras que modelaron las pautas de identificación de sus docentes y estudiantes. $Y$ en este rubro surgen nuevas preguntas también dentro de las corrientes filosóficas: ¿es factible rastrear las influencias del neopositivismo, el existencialismo, el marxismo, la hermenéutica, la Escuela de Frankfurt, el estructuralismo, el deconstructivismo, el pensamiento posmodernista, y otros muchos más a través de huellas o indicios -más o menos 
perdurables- en las gestiones editoriales y en los diseños gráficos de las publicaciones de la Facultad? Y si es así, como es de esperar, pensando en Karl Marx, Wilhelm Dilthey, Max Scheller, Edmund Husserl, Bertrand Russell, Martin Heidegger, Ludwig Wittgenstein hasta Jean-Paul Sartre, Michel Foucault, Jacques Derrida o Pierre Bourdieu, tan solo por citar algunas personalidades, ¿cómo estos filósofos o pensadores influyeron en la evolución y transformación que se materializa en prácticas y bienes de valor intelectual y cultural?

Pero la densidad de los acercamientos conceptuales adquiere connotaciones aún más intricadas. Pensemos en el impacto y el papel que desempeñó Immanuel Wallerstein (2011 [1996]) con su libro Abrir las Ciencias Sociales en la modernidad actual de estas disciplinas y sus nuevas articulaciones con las Ciencias Naturales y, sobre todo, por su apelación al reagrupamiento de la Ciencia ante la explosiva fragmentación disciplinar. Una fragmentación que hoy linda con los márgenes del relativismo. También es oportuno mencionar la participación descollante de tres grandes disciplinas que cambiaron nuestras formas de pensar los discursos y sus "conductas de edición": la Lingüística, la Sociología y la Antropología. Todo esto y mucho más han influido, en forma perentoria y rotunda, en nuestras formas de editar en las universidades (Dujovne, 2018).

Solo hemos mencionado una mínima y arbitraria constelación de concepciones que han "presionado y tensionado" sobre la mayoría de los quehaceres editoriales en la FFyL y que, sin duda, deben ser rastreados y corroborados en los diferentes espacios temporales, tal como se lo propone el presente trabajo y el proyecto que intenta exponer.

Sin embargo, dentro del marco citado, hay que hacer referencia a un campo que hace más de un cuarto de siglo se expande con gran vigor y replantea las formas y procedimientos de muchos estudios universitarios: la Historia de la Lectura (De Diego, 2021). Nuevamente, emerge un insoslayable cuestionamiento: ¿dentro de qué modelo teórico es posible encuadrarla o, al menos, posicionarnos para reflexionar sobre su realidad?

En el comienzo de este texto habíamos planteado que la Historia de la Edición y la Historia de la Lectura estaban subsumidas dentro de la civilización escrita. Ahora bien: ¿cuál es la teoría de la Historia de la Lectura dentro de esa gran área, y si realmente posee una? Esta problemática se visibiliza con fortaleza dado que no existe una teoría o una referencia consentida acerca de sus aspectos conceptuales (Parada, 2015 y 2019).

No obstante, existen varias tendencias que se aproximan a una teoría y, por ende, a dimensiones metodológicas abiertas a una explicación académica. En un primer momento, tanto Roger Chartier como Robert Darnton establecen algunos contenidos en esta problemática. Chartier sostiene -la literatura sobre este tópico 'chartieriano' es muy abundante- la necesidad de determinar "las prácticas y las representaciones" de los lectores (Chartier, 1993a², 1993b y 1999); y Darnton, fundamenta que es indispensable reconocer las "respuestas de los lectores" (Darnton, 1993).

Por otra parte, ya en materia editorial, ambos afirman que no se puede analizar la Historia de la Lectura, sin implementar, a la par, una Historia de la Edición, es decir, un relato de los ámbitos de circulación de la cultura impresa (Darnton, 2008 y 2010). Si bien sus posiciones oscilan desde una visión sostenida en "la representación lectora" (Chartier) y una posición más pragmática anclada en una visión antropológica y simbólica (Darnton), los dos se refieren, en lo medular, a lo mismo: la necesidad de estudiar cómo la lectura y las formas de edición influyeron en las personas y dieron otro sentido a sus vivencias.
2. Especialmente el capítulo: La lectura: una práctica cultural. Debate entre Pierre Bourdieu y Roger Chartier . p. 199-220. 
En dicho esquema de trabajo, el método que emplean estos historiadores es de índole cualitativa, esto es, el método histórico en un contexto de interpretación. El modelo a seguir lo estableció tempranamente Carlo Ginzburg (1981 [1976]) en su famoso libro Elqueso y los gusanos, donde el molinero Menocchio ofrenda su vida como trofeo ante la Inquisición debido a la libre representación de sus lecturas. En un trabajo ya casi legendario Ginzburg denomina a su proceder con el título de "método indiciario", donde "las huellas y los indicios de los lectores" se interrelacionan bajo el amparo de una metodología casi detectivesca (en lo deductivo) y con elementos de Sigmund Freud y Giovanni Morelli (Ginzburg, 2004, 2008 y 2010; Parada, 2013: 38). Por lo tanto, en el momento de fundamentar nuestro objeto de estudio, hay que esbozar la trazabilidad de estas expectativas teóricas signadas por las prácticas y sus representaciones, pero fuertemente enraizadas en una gran diversidad de fuentes documentales plausibles de una aproximación interpretativa.

\section{Hacia un catálogo preliminar de fuentes documentales en el ámbito de la FFyL}

Uno de los ejes más significativos en la Historia de la Edición y en la Historia de la Lectura es la cuestión de las "fuentes documentales". Ya que al momento de encarar toda puesta en texto de estas temáticas se torna crucial la forma de acceso a la masa documentaria que debe ser recopilada y analizada. Por supuesto, esta situación se hace más compleja en el mundo de las producciones editoriales universitarias y en las prácticas lectoras inmersas en sus bibliotecas. Si bien la literatura no es abundante sobre este objeto de estudio, la bibliografía documental puede ser mucho más amplia y variada.

Es oportuno entonces diseñar una enumeración de esas fuentes, aunque sea preliminar o provisional (Cuadro 1). Además, como ocurre en numerosas disciplinas de las Ciencias Sociales, las fuentes para rescatar determinados usos y representaciones suelen ser más ricas de lo que se piensa en primera instancia. De más está decir que varios de los documentos mencionados pueden tener un valor relativo una vez identificados y que otros, que no han sido tenidos en cuenta o que tenían una mirada subalterna, resulten, a la postre, fundamentales para esta clase de estudios.

¿Cuál puede ser, en grandes líneas, el listado provisional de esta documentación que nos puede ayudar en la captura de los lectores y sus prácticas en la universidad? En primer término una fuente se proyecta por su importancia: los registros o formularios de préstamos en la Biblioteca Central y en las bibliotecas de los institutos. Estos documentos son de vital importancia, pues reseñan lecturas verdaderamente realizadas por sus lectores. En un segundo momento, y estrechamente vinculados a los anteriores, están los programas de cada materia donde se puntualiza la bibliografía obligatoria y la bibliografía sugerida o complementaria. Este nexo es esencial, porque el desarrollo de la colección de las bibliotecas está articulado por las demandas de bibliografía que establece cada profesora o profesor para su asignatura. Un tercer elemento a considerar, también en vinculación con los dos anteriores, son los rastros de marginalia que poseen estos libros prestados y presentes en las bibliotecas universitarias: subrayados, aclaraciones, comentarios manuscritos en las páginas de guarda, entre otros muchos, son una de las huellas más visibles de toda representación de la lectura.

En un segundo nivel de significación, aunque en materia de lecturas no existen niveles de ninguna índole, es necesario citar los archivos propiamente dichos de las bibliotecas y, en nuestro caso específico, de las bibliotecas institucionales. Pues en ellos se encuentran numerosos vestigios que hacen a la reconstrucción de las ediciones emprendidas por cada instituto de la Facultad y, por extensión, albergan un conjunto 
de datos sobre las modalidades y emprendimientos lectores. Dentro de estos archivos hay que tener especial cuidado en relevar la totalidad de la correspondencia e intercambios epistolares, donde emergen los distintos actores de la edición y la circulación de las obras, tanto en el interior como en el exterior de las propias unidades académicas. Otra fuente que se imbrica con este grupo son, indudablemente, las Memorias de los institutos y sus bibliotecas que trazan, punto por punto, y en forma detallada, varias actividades editoriales y del lectorado que de no mediar este formato anual caerían, sin duda, en el olvido.

Existe un tercer grupo de fuentes de complejo agrupamiento pero de gran riqueza documental en el núcleo de producción de la FFyL, tales como los siguientes: los reglamentos y comunicaciones vinculados a las bibliotecas, la edición y la compra de libros (la trazabilidad bibliográfica de las partidas presupuestarias en la adquisición de libros), los catálogos editoriales y estudios puntuales sobre la producción editorial (Giunti, Contardi, Ramírez Ibarra, 2019), la Historia Oral y el aporte de sus entrevistas como herramienta para el conocimiento de la esfera editorial, la bibliografía citada al fundamentar el estado actual de un tema en los proyectos de investigación (UBACYT, FILO:CyT, PRIG, etc.), la literatura mencionada en los libros y revistas científicas editadas por la Facultad, las normativas y manuales de procedimientos (relacionados con instancias de la lectura) en la Biblioteca Central y en la de los institutos, los lugares de venta de la producción editorial, el análisis de los contratos de coedición con editoriales privadas, las reseñas y comentarios bibliográficos de obras editadas por la Facultad o que han sido motivo de recensiones en sus revistas especializadas, el estudio de los fundamentos bibliográficos para el cambio de planes en las materias dictadas, los antiguos "ficheros de obras de desiderata" (esto es, de títulos que "se deseaba comprar" y que se adquirieron o no), la iconografía e imágenes de los lectores en "los lugares físicos" de los institutos y salas de lectura en las bibliotecas así como otras zonas (clases, pasillos, patios y espacios de lectura informales), las actividades de extensión de la SEUBE y las ediciones y lectorado que ellas implicaban, las Ferias y Exposiciones del libro proyectadas y realizadas, la "escritura expuesta" en las paredes de diversas dependencias y departamentos (institucional y no institucional), la circulación de las "fichas de cátedra" dentro y fuera de la Facultad, los cursos de posgrado sobre lectura, escritura y temas relacionados con la edición, la presencia en la prensa periódica de autores y ediciones de la Facultad (avisos, recensiones, premios), los estudios sobre la fundación y gestión de la imprenta universitaria, las familias tipográficas utilizadas en determinados interregnos, las estrategias de diseño gráfico, los ensayos sobre las dinámicas de gestación y desarrollo de las colecciones y series de publicaciones, entre otras muchas.

Además, a partir de entender que el espacio de la facultad es aquel que permite compartir la lectura que se acompaña con "el compartir de la escritura", también nos lleva a pensar en otros documentos, que a pesar de su carácter más efímero no deben dejar de ser tenidos en cuenta: cuadernos de apuntes, resúmenes, registros sonoros. Y tras la irrupción del mundo virtual, los correos electrónicos, los campus o redes sociales. Un conjunto de materiales que remiten a prácticas compartidas, fragmentadas, y de difícil sistematización pero relacionados entre sí que explicitan, según cada momento histórico, los usos socializados y las apropiaciones que de los escritos hacen los lectores (Cuadro 1). 
Cuadro 1. Fuentes provisorias para una Historia de la Edición y la Lectura en la FFyL

\begin{tabular}{ll}
\hline Fuentes para una Historia de la Edición & Fuentes para una Historia de la Lectura \\
\hline Materialidades & Colecciones y archivos de las bibliotecas \\
Libros & Registros o formularios de préstamos \\
Fichas de cátedra & en la Biblioteca Central y en las \\
Otros materiales impresos (revistas, & bibliotecas de los institutos \\
actas de congresos) & Marginalia \\
Textos originales entregados y no & Correspondencia e intercambios \\
impresos & epistolares \\
Estudio sobre la Imprenta Universitaria & Avisos, recensiones, premios \\
Familias tipográficas & Reseñas y comentarios bibliográficos \\
Estrategias de diseño gráfico & Iconografía e imágenes de la lectura \\
Gestación y desarrollo de las & Apuntes de clase y resúmenes \\
colecciones & Clases grabadas (audios y videos) \\
Series de publicaciones & Bibliografías de los programas de \\
Catálogos editoriales & materias, seminarios e investigaciones \\
Contratos de coedición con editoriales & Campus virtuales \\
privadas & Redes sociales, correo electrónico, \\
Secretaría de Publicaciones & WhatsApp \\
Reglamentos & Cursos de posgrado, grado, y extensión \\
Actas & sobre lectura y escritura \\
Normativas y manuales de & Jornadas vinculadas a la Historia de la \\
procedimientos & Cultura Escrita \\
Avisos, recensiones, premios & Libros \\
OpFyL (punto de venta al público) & Paper académico \\
Páginas web & Fuentes orales \\
Exposiciones del libro y participación en & \\
ferias nacionales e internacionales & \\
Cursos de posgrado, grado y extensión & \\
sobre temas relacionados con la edición & \\
Jornadas de Edición & \\
Fuentes orales & \\
&
\end{tabular}

De modo que la constelación de fuentes puede resultar casi inabarcable cuando se aborda la Historia de la Edición y la Historia de la Lectura en esta casa de estudios. Resulta imperioso, por añadidura, reflexionar desde un punto de vista ontológico acerca de estos documentos al confrontarlos con el marco teórico y con la coherencia de su propio discurso, dependiendo del documento en el cual se sustente la investigación. Los lectores y los editores delinean parábolas que a primera vista pueden parecer disímiles pero que manifiestan esa típica complementariedad de las distintas disciplinas que forman parte de la Historia de la Cultura Escrita.

\section{Pensar una metodología para una Historia de la Edición y la Lectura en la FFyL}

Profundizando lo antedicho, y cuando se consideran los cambios ocurridos en las últimas décadas en la Historiografía, se encuentra que se modificaron las estrategias con las que se investiga y escribe la Historia del Libro; una historia que devino en Historia de la Edición y se está transformando en Historia de la Lectura; esto es una historia que traslada la mirada a las prácticas asociadas al libro, entendiendo que es necesario tanto el estudio de las formas impresas y sus mecanismos de reproducción, 
control y difusión, como el contexto donde las ediciones nacen hacia la búsqueda de sus lectores potenciales; sin olvidar las formas de recepción, de apropiación y los testimonios que los sujetos registran de sus experiencias lectoras. Sin embargo, si bien estos estudios reconocen ciertas derivas de imprecisión (De Diego, 2021: 53) que pueden superarse en la medida en que demos el salto hacia una Historia de la Lectura, como señala Infantes (1998), no hay que olvidar que la Historia de la Lectura también incluye una Historia de las Bibliotecas, una historia de los libros allí guardados, de las colecciones que han quedado en sus memorias; una historia de las lecturas (posibles) en un proceso que se modifica y transforma a través del tiempo.

Al tomar esto como punto de partida, y con el objetivo de unir la escritura y la lectura con el desarrollo de la educación y el conocimiento, parece pertinente pensar la elaboración de una metodología para una Historia de la Edición y de la Lectura en la Universidad planteando algunas preguntas iniciales que, en palabras de Petrucci (2003:7-9), recuperen la interrelación entre la sociedad y la escritura acerca de quiénes, cómo, y con qué elementos se han desarrollado estas prácticas y mediante con qué dispositivos se registran y difunden las ideas; cómo, cuándo y por qué se edita, para así incorporar el estudio de la interrelación entre la sociedad y la lectura; analizar qué lugar ocupan los libros y las bibliotecas; y, a partir de la relación cotidiana en estos ámbitos con la escritura, los libros y la lectura, cómo se adquieren, interpretan y reconfiguran los textos.

\subsection{Recorridos metodológicos: Historia de la Cultura Escrita}

Se podría comenzar a pensar estas cuestiones proponiendo un juego: cerrar los ojos, mover el dedo, y dejarlo caer en un globo terráqueo: ese es el lugar donde hay que ir. Para empezar a conocer se miran los nombres, la topografía y comienza el viaje con la imaginación, pensando en las personas que habitan ese territorio, sus formas de vida y costumbres. Pero hay otra forma de lo lúdico. El destino es elegido y se llega a él sabiendo que es allí donde se quiere estar presintiendo que este viaje permitiría descubrir cosas nuevas. Aunque hay un giro más que enriquece la propuesta y permite algo más en ese ir alli: se puede elegir el espacio y el tiempo.

Transformado este juego en un artefacto intelectual adecuado a la lógica científica, comenzará un viaje que intentará ayudar a superar los límites actuales y definir nuevas categorizaciones, conceptualizaciones, teorizaciones y metodologías de los objetos que se examinan, con el propósito de comenzar un debate que permita construir, aunque sea modesta y provisionalmente, una epistemología de la Historia de la Edición y de la Historia de la Lectura. De modo que al poder fijar coordenadas se elige un lugar: Perugia y un momento: marzo de 1977, con el propósito de ir al Congreso convocado por Armando Petrucci y Attilio Bartoli Langeli.

Los organizadores del evento se habían propuesto intercambiar un conjunto de ideas en torno a la escritura, la alfabetización y la lectura así como la producción de la cultura a través de lo escrito para confrontar planteos metodológicos que enriquezcan las investigaciones. Esa iniciativa reunió a estudiosos e investigadores de distintas disciplinas, desde historiadores como Franco Cardini o Carlo Ginzburg; paleógrafos como los organizadores Armando Petrucci y Attilio Bartoli Langeli y Guglielmo Cavallo; lingüistas como Giorgio R. Cardona o Raffaele Simone o estudiosos del alfabetismo como Giuseppe Ricuperati, Marina Roggero y Jacques Ozouf (Petrucci, 2002: 13).

Los nombres de los participantes señalan la primera idea que comenzó a nutrir estos estudios, y como ya se ha señalado, se propuso aprovechar las propuestas provenientes de diversos campos del conocimiento a través de la interdisciplinariedad. A partir 
de allí, se pasó a entender que la Paleografía, la Historia, la Lingüística, la Historia de las Bibliotecas, la Historia del Libro, la Filología, la Historia de la Educación y la Alfabetización, la Literatura y la Sociología de la Lectura brindaban elementos para construir una Historia total de la Cultura Escrita que, aún hoy, permite seguir incorporando nuevas perspectivas a trabajar y se sigue ampliando con la Historia de las Emociones, las Humanidades Digitales, la Historia de las Mujeres o las Infancias.

Es posible leer en las actas que fueron publicadas por la Facultad de Filosofía y Letras de la Universidad de Perugia bajo el título de Alfabetismo e Cultura scritta nella storia della società italiana (1978) -también aparecieron parcialmente en una edición especial de la revista Quaderni Storici (Bartoli Langeli y Petrucci, 1978) -que más allá de las cuestiones específicas vinculadas a la Paleografía, estos estudios se propusieron iniciar un discurso común sobre la escritura y sus alcances socioculturales. En ese sentido, Attilio Bartoli Langeli impulsaba a considerar el ambiente de lo escrito en su totalidad, ya que cada una de las evidencias materiales de la escritura remitía a un proceso cultural, a un tipo de alfabetización, a una forma de sociabilidad y, por tanto, merecía un análisis, una descripción y una formalización (Bartoli Langeli, 1978).

En tanto complementando está posición, Armando Petrucci invitaba a estudiar la historia de la producción y los usos sociales de la escritura en una sociedad determinada, independientemente de las técnicas y de los materiales empleados; no solo para las sociedades del pasado sino, además, en el epicentro del mundo contemporáneo, como lo muestra en Scrivere eno. Politiche della scrittura e analfabetismo nel mondo d'oggi (1987).

De modo que la metodología que se pretendía desarrollar ya no solo era para una ciencia que estudiaba las escrituras antiguas, sino una disciplina que se planteaba el estudio global de la historia de los usos y prácticas del escrito, una historia de los signos gráficos, pero también de la función y extensión social de estos; es decir, una historia del libro y la lectura, así como de las formas de producción y conservación de la "memoria del saber" (Castillo Gómez y Sáez, 1994: 134).

Por lo tanto, lo que interesa es destacar esa particular mirada sobre la metodología de abordaje de la cultura escrita, desde la cual se entiende que la difusión social de la información (principalmente a partir de la instrucción) es uno de los principales elementos de desarrollo de un país a través de las memorias de lo escrito, lo editado y lo leído.

Este cambio de paradigma en la Historia de la Cultura Escrita ha sido fundamental ya que no solo comenzó a buscar y conocer quiénes han podido y quiénes no pudieron aprender a escribir y leer sino que, además, orientó su atención a todos los documentos escritos (efímeros, cotidianos, científicos y literarios, entre otros) que si bien tienen la dificultad de caracterizarse por ser materiales dispersos, no inventariados ni individualizados, constituyen fragmentos supervivientes que permiten comprender más y mejor a esa sociedad que los crea, difunde, conserva o destruye (Petrucci, 1998: 15; 2000).

Así, después de un largo período de indefinición conceptual, comenzó a configurarse un abordaje integral del circuito de producción, circulación y recepción de textos (manuscritos e impresos), que tuvo la virtud de combinar el interés por las cualidades técnico-materiales de los textos con el análisis de su contenido y estructura (Castillo Gómez, 2003: 96).

Ahora bien, ¿cómo pasar de estas aproximaciones a un abordaje que profundice, en una descripción densa, la escritura, edición y lectura académica?, ¿cómo estudiar las formas de apropiación y recepción?, ¿cómo teorizar las prácticas que producen los usos de lo escrito?, ¿cómo estudiar las transformaciones que se generan a partir de 
las materialidades?, ¿con qué categorías y conceptos analizar, ajustándolas a su historicidad, las capacidades y conocimientos para la edición y la lectura en la facultad? ¿Cómo pensar una historia que logre superar el análisis de un caso para integrar complementariamente la producción material y la lectura en los espacios universitarios?

\subsection{De la Historia de la Edición a la Historia de la Lectura}

Sin duda, para que los textos adquieran nueva vida al ser recuperados no solo en su significación material sino también como vehículos de prácticas sociales en nuevos sujetos históricos, deberán aplicarse y articularse métodos cualitativos e interpretativos para el tratamiento y el análisis de la documentación (Denzin y Lincoln, 2000). El uso de estas metodologías, en particular las de la observación y comparación -provistas por las Ciencias Sociales- así como las que se instrumentan desde la investigación histórica: heurística, crítica, hermenéutica, síntesis y exposición, son las que contribuirán a estudiar las relaciones en que se desarrolla la edición con los usos y apropiaciones de una comunidad lectora, inserta en entramados sociales, políticos y culturales, que transforma y le da sentido a aquello que se escribe, que se edita y que se lee.

Como se ha señalado, serán fundamentales los aportes de Roger Chartier, Robert Darnton y Carlo Ginzburg, ya que multiplican objetivos y temas, amplían las direcciones de trabajo, los marcos teóricos y las metodologías al entender que los sistemas de comunicación, la cultura y el mundo simbólico no se pueden pensar como una entidad que se baste a sí misma, sino como una lengua a través de la que el poder, las relaciones sociales y la economía se expresan en forma ineludible (Darnton, Chartier y Bourdieu, 2001).

Al volver a esos aportes se entiende que el método indiciario que propone Carlo Ginzburg $(2004 ; 2008)$ permite a través de un cambio de escala, analizar e interpretar detalles que llevan al conocimiento de elementos o circunstancias complejas que, de otra manera, no se percibirían. Complementando esto con la guía de investigación propuesta por Robert Darnton $(1993,2003,2008,2010)$ se pueden encontrar más huellas que reconstruyan el trabajo editorial en la Universidad, estableciendo formas de relación entre el texto, el lector, los contextos y las formas de lectura que se desarrollan. Considerado este objeto impreso desde su materialidad -el papel, los tipos de letras, las imágenes, las encuadernaciones, el formato, el diseño gráfico-, desde su carácter económico -el catálogo, la rentabilidad, las redes comerciales- y en relación con quienes trabajan en los talleres y en los oficios gráficos, permite comenzar el recorrido a nuevos territorios en las investigaciones ya que todos tienen su parte en un trabajo que desde el objeto físico, el libro, transmite mensajes intelectuales (Darnton, 2006). En los libros se hace presente la historia a la vez que hacen la historia, no solo por lo que dicen o cómo lo dicen, sino porque ellos son una marca de su tiempo, sobre todo si son tenidos en cuenta junto a quienes realizan el acto de la lectura.

Mientras que, partiendo de distinguir y articular los diferentes tiempos en cada momento histórico, Roger Chartier (1993b, 1999, 2000, 2007, 2021) invita a pensar cómo lo escrito transforma la cultura, difunde nuevas formas de socialización y nuevos modos de estar en el mundo, al pensar de manera más compleja y dinámica las relaciones que atraviesan los sistemas de percepción según las condiciones de producción de los sujetos sociales. Lo que se está poniendo en el centro del debate es, no solo la cuestión de qué textos o cómo eran o son leídos, sino cual es "el juego de las reglas" que explica qué es leer históricamente (Chartier, 2000).

Poner la mirada en el juego de las reglas permite darle relieve a las formas materiales (esto es la descripción de los objetos escritos para ocuparse de las motivaciones sociales, económicas o políticas que rige la producción textual), pero avanzar un paso 
más, ya que estas contienen claves importantes para considerar tanto los horizontes de lectura como las apropiaciones de los lectores. Sin embargo, ante la existencia de tantos lectores que no han dejado huellas, ¿cómo es posible su reconstrucción?

Desde un punto de vista metodológico, a partir de un análisis de la cultura escrita que se concentre en las múltiples relaciones que se establecen entre los discursos, las prácticas (las apropiaciones concretas, individuales o colectivas de lo escrito) y las representaciones (las imágenes que una sociedad construye sobre sí misma y sobre las prácticas a que da lugar). Sin dejar de interrelacionar esto con los tiempos de lo escrito: la producción y adquisición, el uso y apropiación, hasta las formas de conservación. En palabras de Petrucci, el objetivo debe ser recuperar la interrelación entre la sociedad y la escritura afrontando el qué, el cuándo, el dónde, el cómo, el quién y el para qué de las prácticas escritas (Petrucci, 2003: 7-9).

Aquí, hay que detenerse para complejizar a la vez que desentrañar otro elemento importante en este intento de construcción metodológica: la lectura. Giorgio Agamben señala en "La dificultad de leer" (2016), que no va a hablar de la lectura y de sus riesgos, sino de un peligro anterior: la imposibilidad de leer. La ilegibilidad es lo que parece suceder al intentar construir una Historia de la Lectura, la presencia de una opacidad que resiste toda interpretación.

Interesante para reflexionar sobre el contenido de los textos, no solo los editados sino también los guardados en las bibliotecas de la facultad, así como los que circulan en sus aulas y pasillos. No porque esos libros estén pensados para unos ojos que no pueden leerlos o no puedan comprenderlos o resignificarlos, sino que hablan de otro caso de no lectura, se refiere a los libros que están a la espera de ser leídos. Entonces, pensar la dificultad de la lectura desde ese lugar entre lo escrito y lo ilegible.

Para ello, deberían ampliarse los conceptos y, en consecuencia, hablar de un ámbito de policontextualidad. Y en este contexto desentrañar las comunidades de lectura, estudiar las nuevas prácticas de alfabetización y entrecruzar la lectura con la escritura pero sin separarlas de la oralidad y lo audiovisual; donde la lectura y la escritura no se reducen al mundo del libro sino que, además, participan otros formatos y lenguajes; donde la coexistencia de los libros en papel y los digitales, tal como explica Roger Chartier, es una nueva forma de construcción de los discursos del saber y las modalidades específicas de su lectura; y donde estas prácticas se encuentran articuladas en torno a la tríada oralidad-escritura-lectura (Chartier y Rodríguez de las Heras, 2001).

Pero volvamos a una definición de la Historia de la Lectura. Siguiendo a Alejandro E. Parada podemos decir que esta se ha caracterizado por ser una disciplina con una renovada vitalidad dentro de las Humanidades y las Ciencias Sociales, una disciplina en construcción teórica que dependerá de la habilidad de cada historiador para descubrir que llevó (y lleva) a los hombres y mujeres a leer, cualesquiera hayan sido sus prácticas, soportes y representaciones (Parada, 2013; 2019).

La construcción de una historia de este tipo implica asumir como fuentes diferentes materiales (orales, escritos, impresos o multimediales) que tienen que ver, ajustado a lo que se trabaja en este caso, con la escritura y la lectura en y desde la universidad, lo cual exige la aplicación de una variedad de métodos para su análisis. De este modo, no solo se trata de interpretar los documentos que se tienen, sino también convertir en objetos históricos la realidad que los trasciende, tanto desde su contenido textual como de su materialidad. 


\subsection{Un recorrido posible}

¿Cómo podría pensarse una aproximación que ayude a dar cuenta de la especificidad de la edición y la lectura en la Facultad de Filosofía y Letras de la Universidad de Buenos Aires?, ¿de qué manera diseñar una descripción que explore el inmenso yacimiento de los documentos y contestar las preguntas esenciales del quién, qué, dónde y cuándo, para pasar, en una segunda instancia, a su interpretación?

Podría proponerse como primer paso una descripción, donde no se desestime la utilización de métodos cuantitativos, ya que estos estudios, lejos de ser estériles, brindan la base necesaria para intentar contestar las preguntas más complejas del por qué y cómo de los cambios en las formas de comunicación científica y acceso al conocimiento.

Tomando en cuenta que la larga duración de la Historia de la Cultura Escrita, muestra en cada mutación la coexistencia de objetos y gestos antiguos con las nuevas técnicas y prácticas (Chartier, 2007), el siguiente paso sería establecer las relaciones entre edición, imprenta y transformaciones tecnológicas, evaluando el impacto de publicar con imprenta propia, compararlo con aquellas otras circunstancias donde se realiza sin ella, para llegar a indagar en las ventajas o desafíos que presenta la edición digital. Y luego avanzar en el estudio de su producción: libros, revistas, fichas de cátedra; es decir, el conjunto de materiales que se encuentran unidos a la enseñanza y la investigación, pero también los que la superan pensando en formas editoriales diseñadas para difundir el conocimiento hacia la comunidad. Esto implica tratar de comprender la evolución de la organización de una oficina de publicaciones, desde los reglamentos, formas de financiamiento, miembros, entre otras muchas cuestiones que también incluyen el diseño de las colecciones, la selección de colores, la estructura tipográfica y el armado del catálogo hasta las formas de comercialización y difusión de los materiales.

Esta combinación de factores brinda elementos para comenzar a indagar en las mutaciones de las prácticas de lectura y las transformaciones en las relaciones con el libro, desde su compra hasta la lectura en las bibliotecas, el uso de las fotocopias y apuntes, sin dejar de incluir, la digitalización y el acceso a los materiales en la red.

Siguiendo la argumentación de Chartier (2007), no debe olvidarse que el universo digital ha permitido la construcción de un nuevo tipo de libro, estructurado en estratos discursivos hipertextuales, que cambia la lógica de la argumentación, que ya no es lineal ni secuencial, sino abierta y relacional, transformando profundamente los discursos del saber donde cada lector construye interpretaciones cambiantes de fragmentos, que no implican la comprensión de las obras en su singularidad.

\section{Conclusiones}

Por lo expuesto, el presente desafío teórico metodológico, estructurado en el marco de un debate abierto, posee múltiples vertientes y complejidades. Pues el objeto de estudio propuesto bajo el tema "Entre lo editado y lo leído en la Facultad de Filosofía y Letras de la Universidad de Buenos Aires" prácticamente carece de antecedentes previos con un abordaje sistemático. Por añadidura, se intenta configurar un marco reflexivo y documental para diseñar e implementar su análisis y puesta en texto. A todo esto, y en esa vertiente radica uno de sus aspectos de mayor interés, se trata de comenzar una discusión que permita pensar y articular dicho marco para que pueda readaptarse a las realidades de otras facultades de la Argentina. 
Estudiar el contexto teórico y las posibles metodologías que deben estructurarse para reflexionar sobre la edición y la lectura en la FFyL, resulta un requisito indispensable para instrumentar las prácticas y representaciones editoriales y lectoras a lo largo de más de un siglo en esa casa de estudios.

Pero, por sobre todo, antes de comenzar con los aspectos prácticos y operativos de su estudio, es necesario conceptualizar los modos y procedimientos de llevarlo a cabo desde el punto de vista académico.

Se trata en esta instancia, de evitar algo que acontece en este tipo de estudios: que en un primer paso se construye la escritura y las operaciones discursivas y, luego, en un segundo momento, cuando ya existe una producción escrita significante (pero heterogénea y dispersa) se sustancia, a partir de esa práctica, el encuadramiento teórico. De ahí, la necesidad de volver a reflexionar y entender las categorías que se manejan para explicar la Cultura Escrita, sumándole las mutaciones que desafían la identificación del libro como obra y el libro percibido como objeto, presentando un dispositivo hipertextual que transforma las prácticas lectoras. En este marco, lo que realmente se impulsa, es gestar preliminarmente todo tipo de ideas y métodos, para así adecuar y articular la escritura que debe ceñirse a ese modelo.

La Facultad de Filosofía y Letras de la Universidad de Buenos Aires reúne todos los requisitos pautados por la diversidad de su universo editorial, donde el diseño gráfico, las políticas editoriales y la riqueza de su producción impresa, deviene en un llamado para su interpretación desde los postulados modernos, y aún en construcción, de la Historia de la Cultura Escrita e Impresa.

La concreción de este contexto de conceptos y procederes puede resultar en una oportunidad inmejorable (pero siempre perfectible en sus modificaciones y debates) de proponer una respuesta a algunas de las preguntas que hemos planteado en este texto: ¿cómo se construyeron esos objetos materiales que denominamos "libros" desde la mirada de una facultad, en la cual la trazabilidad del mercado y la búsqueda de rentabilidad no son tan importantes como la difusión de los saberes universitarios?, ¿cómo evolucionó e influyó el diseño gráfico, durante el interregno de más de una centuria, en el lectorado que los consumía dentro de esa facultad, tanto en la esfera docente como estudiantil?, ¿qué aspectos y matices debemos tener en cuenta para saber o intuir cualitativamente si los lectores o las lectoras inmersos en ese ambiente, fueron capaces de generar prácticas y apropiaciones de la lectura distintas al circuito comercial de lo impreso?, ¿cuál fue el papel de los acervos bibliográficos de la Biblioteca Central y los de los institutos, para incidir y escenificar las representaciones de sus propios usuarios?, ¿cómo articular en un diálogo común las particularidades de la edición, los libros y la lectura para dar forma a un marco teórico crítico y reflexivo de las prácticas culturales asociadas a la cultura de lo impreso?; entre una gran diversidad de interrogantes que se manifiestan al desarrollar este encuadre contextual de trabajo en su amplia prospectiva.

Así, este artículo, con las complejidades y ambivalencias de una dimensión inaugural, pretende establecer una discusión abierta y unas respuestas provisionales sobre las formas y las conceptuaciones indispensables de las producciones editoriales y lectoras en las entrañas de una facultad que ya ha cumplido 125 años y, por supuesto, en la realidad histórica y presente de los 200 años de la Universidad de Buenos Aires. El desafío está planteado. 


\section{Q Referencias bibliográficas}

" Agamben, Giorgio. (4 de octubre de 2016.) La dificultad de leer. En Nexos. https://cultura.nexos.com.mx/sobre-la-dificultad-de-leer/> [Consulta: 27 agosto 2021].

》 Alfabetismo e Cultura scritta nella Storia della società italiana. Atti del Seminario tenutosi a Perugia il 29-30 marzo 1977. 1978. Perugia: Università degli Studi di Perugia.

» Bartoli Langeli, Attilio. 1978. Premessa alla parte monografica. En Quaderni Storici. No. 38, 437-450.

»Bartoli Langeli, Attilio y Armando Petrucci, cur. 1978. Alfabetismo e cultura scritta. En Quaderni Storici. No. 38, 437-700.

》Bourdieu, Pierre. 1999. Intelectuales, política y poder. Buenos Aires: Eudeba.

"Bourdieu, Pierre. 2002. Campo de poder, campo intelectual. Itinerario de un concepto. Buenos Aires: Montressor.

"Castillo Gómez, Antonio. 2003. Historia de la cultura escrita: ideas para el debate. En Revista Brasileira da Educação. No. 3, 93-124. < https://periodicos.uem. $\mathrm{br} / \mathrm{ojs} /$ index.php/rbhe/article/view/38710> [Consulta: 12 junio 2021].

»Castillo Gómez, Antonio. 2015. La Historia social de la cultura escrita. Una entrevista con Antonio Castillo Gómez. [Entrevistadora: Cristiani Bereta da Silva] En Revista Tempo e Argumento. Vol. 7, no. 15, 229-242. . <http://www.revistas. udesc.br/index.php/tempo/article/view/2175180307152015229/4726> [Consulta: 17 julio 2017].

»Castillo Gómez, Antonio y Carlos Sáez. 1994. Paleografía versus alfabetización. Reflexiones sobre historia social de la cultura escrita. En Signo. Revista de Historia de La Cultura Escrita. No. 1, 133-168.

»Chartier, Roger, dir. 1993a. Prácticas de la lectura. La Paz: Plural Editores.

»Chartier, Roger. 1993b. De la Historia del libro a la historia de la lectura. En su Libros, lecturas y lectores en la Edad Moderna. Madrid: Alianza. p. 13-40.

"Chartier, Roger. 1999. El mundo como representación. Barcelona: Gedisa.

»Chartier, Roger. 200o. El juego de las reglas: lecturas. Buenos Aires: Fondo de Cultura Económica.

»Chartier, Roger. 2007. La universidad y la edición. Pasado, presente, futuro. En Polo Pujadas, Magda, coord. Innovación y retos de la edición universitaria. Madrid-Logroño, Unión de Editoriales Universitarias Españolas (UNE) y Universidad de La Rioja. p. 13-28.

»Chartier, Roger. 2008. Escuchar a los muertos con los ojos. Lección inaugural en el Collège de France. Buenos Aires: Katz.

"Chartier, Roger. 2021. Presencias del pasado: libros, lectores y editores. Valencia: Universitat de Valencia.

"Chartier, Roger y Jean Hébrard. 1999. Prólogo: morfología e historia de la cultura escrita. En Petrucci, Armando. Alfabetismo, escritura, sociedad. Barcelona: Gedisa. p. 11-21. 
»Chartier, Roger y Antonio Rodríguez de las Heras. 2001. El futuro del libro y el libro del futuro. Una conversación entre Roger Chartier y Antonio Rodríguez de las Heras. En Litterae. Cuadernos sobre Cultura Escrita. No. 1, 11-40.

"Chicote, Gloria, ed. 2015. Redes intelectuales en América Latina: los universos letrado y popular en la primera mitad del siglo XX. Rosario: Prohistoria ediciones.

»Darnton, Robert. 1993. Historia de la lectura. En Burke, Peter, ed. Formas de hacer Historia. Madrid: Alianza. p. 177-208.

»Darnton, Robert. 2003. El coloquio de los lectores. Ensayos sobre autores, manuscritos, editores y lectores. México: Fondo de Cultura Económica.

"Darnton, Robert. 2006. El negocio de la llustración: historia editorial de la Encyclopédie, 1775-180o. México: Fondo de Cultura Económica.

»Darnton, Robert. 2008. ¿Qué es la historia del libro? En Prismas. Revista de historia intelectual. No. 12, 135-155. <http://historiaintelectual.com.ar/wp-content/ uploads/2015/11/Prismas_12_2008.pdf> [Consulta: 11 junio 2021].

»Darnton, Robert. 2010. ¿Qué es la historia del libro? En su El beso de Lamourette. Reflexiones sobre la historia cultural. Buenos Aires: Fondo de Cultura Económica. p. 117-146.

»Darnton, Robert, Roger Chartier y Pierre Bourdieu. 2001. Diálogo a propósito de la historia cultural. En Archipiélago: Cuadernos de crítica de la cultura. No. 47, 41-58.

»De Diego, José Luis. 2021. Historiar la lectura: un desafío que cumple veinticinco años. En Reseñas/CeLeHis. Año 8, no. 22, 52-61. <https://fh.mdp.edu.ar/revistas/index.php/rescelehis/article/view/5075/5608> [Consulta: 12 agosto 2021].

"Denzin, Norman K. e Yvonna S. Lincoln, eds. 2000. Handbook of Qualitative Research. 2nd. ed. Thousand Oaks: Sage Publications.

»Dujovne, Alejandro. 2018. "Efectos de lectura”. Problemas y propuestas para el estudio de las relaciones entre campo editorial y campo académico en las Ciencias Sociales y Humanas. En Prismas. Vol. 22, no. 2, 179-184. <http://www. scielo.org.ar/scielo.php? script $=$ sci_arttext\&pid $=$ S1852-04992018000200261\&l $\mathrm{ng}=\mathrm{es} \& \mathrm{nrm}=\mathrm{iso}>$. [Consulta: 17 noviembre 2021].

»Ginzburg, Carlo. 1981 [1976]. El queso y los gusanos. El cosmos según un molinero del siglo XVI. Barcelona: Muchnik Editores.

" Ginzburg, Carlo. 2004. Tentativas. Rosario: Prohistoria ediciones.

" Ginzburg, Carlo. 2008 [1986]. Indicios: raíces de un paradigma de inferencias indiciales. En su Mitos, emblemas, indicios. Barcelona: Gedisa. p. 185-239.

"Ginzburg, Carlo. 2010. El hilo y las huellas: lo verdadero, lo falso, lo ficticio. Buenos Aires: Fondo de Cultura Económica de Argentina.

» Giunti, Graciela M., Silvia Contardi e Ivalú Ramírez Ibarra, comps. 2019. Libros de FILO: 122 años publicando. Edición corregida, ampliada y actualizada. Buenos Aires: Instituto de Investigaciones Bibliotecológicas, Facultad de Filosofía y Letras, Universidad de Buenos Aires. <http://publicaciones.filo.uba.ar/libros-defilo-122-a\% $3 \%$ B10s-publicando> [Consulta: 20 septiembre 2020].

"Infantes, Víctor. 1998. La mirada en la escritura. Una historia de la lectura y del lector. En Bulletin Hispanique. Tomo 100, No. 2, 333-341. <doi : https://doi. org/10.3406/hispa.1998.4976> 
" McKenzie, Donald F. 2005. Bibliografía y sociología de los textos. Madrid: Akal.

»Parada, Alejandro E., dir. 2013. Cruces y perspectivas de la cultura escrita en la Argentina: historia de la edición, el libro y la lectura. Buenos Aires: Instituto de Investigaciones Bibliotecológicas, Facultad de Filosofía y Letras, Universidad de Buenos Aires.

"Parada, Alejandro E. 2015. ¿Por qué hoy la Historia de la Lectura? En Chicote, Gloria, ed. Redes intelectuales en América Latina: los universos letrado y popular en la primera mitad del siglo XX. Rosario: Prohistoria ediciones. p. 15-29.

"Parada, Alejandro E. 2019. Lectura y contralectura en la Historia de la Lectura. Buenos Aires: Eduvim.

»Petrucci, Armando. 1987. Scrivere e no. Politiche della scrittura e analfabetismo nel mondo d'oggi. Roma: Editiori Riuniti.

»Petrucci, Armando. 1998. Historia de la escritura e historia de la sociedad. Valencia: Universitat de València.

»Petrucci, Armando. 1999. Alfabetismo, escritura, sociedad. Barcelona: Gedisa.

»Petrucci, Armando. 2000. Escrituras marginales y escribientes subalternos. En Signo. Revista de Historia de la Cultura Escrita. $\mathrm{N}^{\circ}$ 7, 67-75. <http://hdl.handle. net/10017/7559> [Consulta: 1 septiembre 2021].

"Petrucci, Armando. 2002. Armando Petrucci: un paseo por los bosques de la escritura. Una entrevista de Antonio Castillo Gómez. En Litterae. Cuadernos sobre Cultura Escrita. No. 2, 9-37. <https://dialnet.unirioja.es/servlet/ articulo?codigo $=786124>$ [Consulta: 12 julio 2021].

"Petrucci, Armando. 2003. La ciencia de la escritura. Primera lección de paleografía. Buenos Aires: Fondo de Cultura Económica.

"Sassen, Saskia. 2010. Territorio, autoridad y derechos. De los ensamblajes medievales a los ensamblajes globales. Buenos Aires: Katz Editores.

"Sassen, Saskia. 2012 [2007]. Una sociología de la globalización. Buenos Aires: Katz Editores.

"Sudjic, Deyan. 2014. B de Bauhaus: un diccionario del mundo moderno. Madrid: Turner.

»Valinoti, Beatriz Cecilia. 2013. Hacia una Historia de la edición, el libro y la Lectura. Revisitando conceptos y categorías. En Parada, Alejandro E., dir. Cruces y perspectivas de la cultura escrita en la Argentina: historia de la edición, el libro y la lectura. Buenos Aires: Instituto de Investigaciones Bibliotecológicas, Facultad de Filosofía y Letras, Universidad de Buenos Aires. p. 59-87.

"Wallerstein, Immanuel, coord. 2011 [1996]. Abrir las ciencias sociales. Informe de la Comisión Gulbenkian para la reestructuración de las ciencias sociales. México: Siglo XXI editores. 
